Revista lus et Praxis, Año 20, No 1, 2014, pp. $351-362$

ISSN 0717 - 2877

Universidad de Talca - Facultad de Ciencias Jurídicas y Sociales

"Crítica a la crítica de Jean Pierre Matus Acuña y María Carolina Peña y Lillo Tolosa

a la investigación '¿Por qué aumenta la población penal en Chile?

Un estudio criminológico longitudinal"

Sebastián Salinero Echeverría

Colaboración recibida el 15 de enero y aprobada el 17 de febrero de 2014

\title{
Crítica a la crítica de Jean Pierre Matus Acuña y María Carolina Peña y Lillo Tolosa a la investigación "¿Por qué aumenta la población penal en Chile? Un estudio criminológico longitudinal"
}

\section{Sebastián Salinero ECheVerría*}

En el № 2 de la Revista lus et Praxis, correspondiente al año 2012, el profesor Jean Pierre Matus Acuña y su alumna doña María Carolina Peña y Lillo Tolosa desarrollan una crítica a la investigación que realicé y publique en esta revista, titulada: "¿Por qué aumenta la población penal en Chile? Un estudio criminológico longitudinal", trabajo que se aboca a analizar los factores y las respectivas causas del aumento de la población penal en Chile, fijando como límite territorial y temporal, lo ocurrido a nivel país y lo acontecido entre los años 2000 y 2009.

Aclaro, desde ya, que esta contestación tardó no por falta de deseo en hacer frente a un buen cuestionamiento de tan distinguidos contradictores, sino por la necesidad de verificar si el tiempo les daba la razón a ellos o, por el contrario, yo mantenía mis argumentos. Finalmente y entendiendo que el debate enriquece, siempre que se realice en un marco de respeto, debo indicar que persisto con mi posición original sobre la base de lo que desarrollaré a continuación.

Mis críticos sientan las bases de su juzgamiento en diversos y variados aspectos. En particular, propician la tesis basada en que el aumento de la población penitenciaria tendría como causa el incremento de las tasas de criminalidad -en el estudio cuestionado se sostiene una desvinculación-; también se pone en duda que el mayor ingreso de personas al sistema penitenciario se deba al impacto causado por la Reforma Procesal Penal. Reconocen que si bien ésta ha implicado una reducción en el tiempo de duración de los procesos judiciales y un incremento en el número de sentencias definitivas condenatorias, no se pone atención al tipo de procedimiento del cual emana esta condena y que la probabilidad que ella establezca una pena privativa de libertad, de modo efectivo, es significativamente baja; además se cuestiona, por un lado, la falta de

\footnotetext{
* Investigador y docente del Centro de Estudios de Derecho Penal de la Universidad de Talca. Magister (Universidad de Talca) y Doctor en Derecho (Universidad de Lérida). Correo electrónico: ssalinero@utalca.cl.

Agradezco sinceramente la colaboración en metodología del profesor Luis Vial Recabarren.
} 
sustento empírico de que el aumento de las tasas de encarcelamiento obedezca a la existencia de leyes que favorecerían tales procesos y, por otro lado, el no probado aumento en los tiempos de privación de libertad; para finalmente, de un modo inconexo a lo sostenido, se refuta que la aplicación de la Ley № 18.216 sea un instrumento que ayude a descomprimir los recintos penitenciarios.

Partiendo por la primera observación -enfática por lo demás-, en orden a sostener que el aumento de la población penitenciaria encontraría como causa el incremento de la actividad criminal en los delitos de mayor preferencia, debo señalar que es una situación que fue descartada a priori en la investigación, y también lo es a posteriori por razones metodológicas, teóricas y empíricas concretas de nuestra realidad nacional.

En efecto, desde el punto de vista metodológico, el único elemento de juicio ofrecido en la crítica para sostener una vinculación entre el incremento penitenciario y la actividad criminal fueron los datos de las tasas de denuncia (estadísticas oficiales). Sin embargo, esa operación adolece de defectos insoslayables, como es que las estadísticas oficiales sólo muestran la punta del iceberg, pero no el volumen real "sumergido" de delincuencia o, dicho de otro modo, no considera la cifra negra (delitos no denunciados), pues no son un instrumento idóneo para informar sobre el volumen, estructura, dinámica y desarrollo del fenómeno delictivo real'. En Sociología Criminal se utiliza el concepto de "atrición" para designar el distanciamiento de las cifras oficiales (los delitos denunciados) y las reales (el total de delitos, incluidos los no denunciados). Así, podemos decir que las estadísticas oficiales no muestran aritméticamente los delitos efectivamente cometidos en un tiempo y lugar determinados, sino sólo los delitos estadísticamente reflejados y/o la predisposición de las víctimas a denunciar los delitos. Por todo ello, en Criminología se prefiere las encuestas de victimización para "medir" la delincuencia y no las estadísticas por todos los problemas asociados que tienen. Es tal la discrepancia entre ambos instrumentos, que Paz Ciudadana corroboró para nuestra realidad que entre los años 2005 y 2012, mientras las encuestas de victimización reflejaban tendencias a la baja, las tasas de denuncia mostraban una situación diametralmente contraria (aumento con variaciones anuales). ${ }^{2}$

Por otro lado, la tesis vinculatoria padece de sustento teórico en el estado actual de la Criminología. Con un argumento de autoridad se señala que la Criminología positiva basada en estudios econométricos ha demostrado que las tasas de criminalidad y de encarcelamiento guardan estrecha relación como

1 García-Pablos de Molina, Antonio (2008): Tratado de Criminología, 4a Ed. (Valencia: Tirant lo Blanch), p. 257; Las encuestas son el instrumento idóneo para medir la delincuencia, véase GARRIDO, Vicente; Stangeland, Per; Redondo, Santiago (2006): Principios de Criminología, $3^{\text {a }}$ Ed. (Valencia: Tirant Lo Blanch), p. 931.

2 Véase Paz Ciudadana, Balance de Delincuencia 2012, p. 21. Disponible en: www.pazciudadana.cl. 
variables dependientes del comportamiento criminal. No obstante, diversos teóricos con estudios empíricos se han encargado de demostrar justamente lo contrario, esto es, la notoria desvinculación entre estas variables. Así por ejemplo, Aebi y Kuhn concluyeron que no existe correlación entre las variables tasa de encarcelamiento y tasa de delincuencia o, cuando existe, es negativa y no significativa ${ }^{3}$. El escandinavo Lappi-Seppälä mostró la evidencia de tres países en los que la tendencia al encierro sigue evoluciones distintas con respecto a las tasas de delincuencia: desde 1980 hasta hoy, Finlandia ha reducido su número de presos mientras sus tasas de delincuencia aumentaban; Canadá ha mantenido estables tanto la cantidad de delitos como la de condenados; y E.E.U.U. ha multiplicado exponencialmente el número de presos mientras sus niveles de delincuencia descendían ${ }^{4}$. Recientemente, el estudio longitudinal del Instituto Urbano en E.E.U.U. (1980-2012), sobre prisiones federales, atribuye el alza de la población penal no a la existencia de mayor delincuencia, sino a una serie de reformas de mano dura contra el crimen, que incluyen sentencias draconianas con mínimos obligatorios y a la eliminación de la libertad condicional por un delito federal cometido después de $1987^{5}$. Por su parte, en Inglaterra y Gales, un informe del Ministerio de Justicia de 2013, atribuye el incremento de la población penal debido a que los tribunales aumentaron la probabilidad de condena cada año entre 1993 y 2002, y porque los delincuentes han estado viviendo en la cárcel por más tiempo ${ }^{6}$. Otrora, ya Lemert había indicado que la variable del número de presos debía dejar de ser vista como una variable dependiente de la delincuencia, hasta el punto de proponer a esta variable como independiente de la misma ${ }^{7}$, es decir, todo lo contrario a lo que profesan mis críticos. En la misma línea anterior, ya se venían manifestado Rusche y Kirchheimer, los cuales han

\footnotetext{
3 AEBI, Marcelo; KuHN, André (2000): "Influences on the prisioners rate: Number of entries into prison lenght of sentences and crime rate", en: European Journal on Criminal Policy and Research (№ 8), pp. 65-75.

4 LapPI-SeppäLÁ, Tapio (2008): "Confianza, bienestar y economía política. Explicación de las diferencias en materia de política penal", en: Alfonso Serrano Maíllo; José Luis Guzmán Dálbora (Eds.), Procesos de infracción de normas y de reacción a la infracción de normas: dos tradiciones criminológicas. Nuevos estudios en homenaje al profesor Alfonso Serrano Gómez (Madrid, Dykinson), pp. 335-372, pp. 345 y ss.

5 . Mallik-Kane, Kamala; Parthasarathy, Barbara; Adams, Williams (2012): "Examining Growth in the Federal Prison Population, 1998 to 2010", en: Research Reporte (septiembre). Disponible en: http:// www.urban.org/UploadedPDF/412720-Examining-Growth-in-the-Federal-Prison-Population.pdf [visitado el 28/11/2014]. La población penitenciaria federal de EE.UU. ha aumentado casi un 790 por ciento desde 1980, con cerca de 25.000 reclusos a 219.000 en 2012.

6 Ministerio de Justicia del Reino Unido (2013): "Story of the Prison Population: 1993-2012 England and Wales". Disponible en: https://www.gov.uk/government/publications/story-of-the-prison-population-1993-2012 [visitado por última vez el 21/04/13].

7 LeMERT, Edwin (1967): Human deviance, social problems \& social control (New Jersey: Prentice-Hall), p. 18.
} 
entendido la influencia de otras causas en la variación de la población penal ${ }^{8}$. Finalmente, para el caso español, el reciente estudio de González Sánchez ha venido a manifestar la falta de una relación directa entre la delincuencia (medida por tasa de denuncias) y el número de presos ${ }^{9}$.

Para seguir con el análisis en esta parte de la crítica, desde la óptica de la evidencia empírica actual, debo señalar que la tesis sostenida por mis críticos también adolece de sustento basado en la experiencia, pues si observamos el indicador que propusieron, denominado Casos Policiales -que se enmarca genéricamente dentro de lo que se conoce como estadísticas oficiales-, pero a nivel país y no reducido a la Región Metropolitana como se propone, y jugando también con el plazo propuesto -pese a que el indicado en el estudio cuestionado es menor-, debo señalar que no se detecta una correlación entre su incremento y el manifestado para la población penal. Si observamos la Tabla 1 podemos avizorar que mientras el aumento de la población penal, en cuanto a su frecuencia absoluta, es constante desde el año 2005 al 2010 y luego presenta un descenso a partir de ese año hasta el 2012, no lo es así para los casos policiales que presentan un comportamiento irregular, logrando un incremento sólo hasta el año 2009 para luego presentar un descenso el 2010, volviendo a alzarse el 2011 y nuevamente tener una reducción significativa en el 2012. Además, si analizamos las variaciones anuales nos encontraremos con que estas tampoco guardan la correspondencia que, siguiendo la tesis antagónica, se debiera presentar.

Tabla 1. Población penal v/s Casos policiales

\begin{tabular}{|c|c|c|c|c|}
\hline Año & Población penal & Variación \% & Casos policiales & Variación \% \\
\hline 2005 & 37.033 & - & 500.574 & - \\
\hline 2006 & 39.417 & 6,40 & 505.317 & 0,94 \\
\hline 2007 & 43.602 & 10,60 & 551.866 & 9,21 \\
\hline 2008 & 49.359 & 13,20 & 569.747 & 3,24 \\
\hline 2009 & 50.923 & 3,10 & 616.372 & 8,18 \\
\hline 2010 & 52.610 & 3,30 & 597.987 & $-2,99$ \\
\hline 2011 & 51.390 & $-2,32$ & 654.828 & 9,50 \\
\hline 2012 & 49.351 & $-3,97$ & 597.629 & $-8,74$ \\
\hline
\end{tabular}

Fuente: Elaboración propia con los datos obtenidos desde Gendarmería de Chile y Subsecretaría de Prevención del Delito del Ministerio del Interior.

8 Rusche, Georg; KirChHeimer, Otto (1939): Punishment and Social Structure (Nueva York, Columbia University Press).

9 GonzÁlez SÁnchez, Ignacio (2011): "Aumento de presos y Código penal. Una explicación insuficiente", en: RECPC (Año 4, № 13), pp. 1-22. 
Para finalizar, en relación a este capítulo del cuestionamiento, la afirmación en torno a la relación inversamente proporcional entre el menor tiempo de duración de las condenas efectivas y mayores tasas de criminalidad, lo cual es respaldado con sendos estudios (citados al pie), es una temática que no fue abordada y es una afirmación que no sólo no se sostuvo en la investigación criticada, sino que es una proposición compartida y, por lo tanto, no es objeto de discusión.

La segunda crítica dice relación con la falta de análisis del tipo de procedimiento mediante el cual se obtiene una sentencia condenatoria y que la probabilidad de que ella sea de cumplimiento efectivo o en la cárcel -sin beneficios-, es significativamente baja. Todo a propósito de haber afirmado el impacto de la Reforma Procesal Penal como causante del mayor ingreso de personas al sistema carcelario.

Sobre el punto, es menester indicar que si bien las estadísticas del Ministerio Público del año 2011 establecen que sólo una pequeña fracción de los casos ingresados a esa institución terminó en condena $(23,63 \%)$ y sólo un porcentaje ascendente a un poco más del $7 \%$ de los casos en los que existían imputados conocidos terminó con una pena privativa de libertad (sin beneficios), se desconoce una magnitud física importante a tener en consideración, como es el volumen total gestionado por las instituciones del Sistema Penal y la significancia en términos absolutos del índice de condenados a una pena privativa de libertad.

En efecto, partiendo por lo falaz de la proposición en orden a sostener que el estudio cuestionado afirma que el Sistema Procesal Penal está diseñado -o se haya implementado- para aumentar el número de personas condenadas a penas privativas de libertad, debo indicar que, al igual que lo han dicho otros estudios $^{10}$, sólo se sostuvo un efecto que ha producido la Reforma, como es su contribución al incremento del número de presos; situación que acontece, en particular, por la capacidad que ha tenido esta nueva estructura orgánica en el management del sistema de justicia penal, el cual ha permitido, por ejemplo: mayores ingresos y mayores términos de los procesos judiciales, ha sextuplicado la probabilidad de condena desde los ocasos del antiguo sistema procesal penal (hasta el año 2009, época final del estudio), ha generado una palmaria celeridad en la tramitación de los procesos judiciales y en los denominados procesos de autoincriminación (procedimiento simplificado y abreviado), los que de manera inmediata y mediata han contribuido al incremento penitenciario, ya sea permitiendo una segura y acelerada sentencia condenatoria, o bien, facilitando

\footnotetext{
10 Álvarez Tuza, Pablo; Marangunic Hinojosa, Antonio; Herrera BilbaO, Raúl (2007): "Impacto de la reforma procesal penal en la población carcelaria del país", en: Revista de Estudios Criminológicos y penitenciarios (diciembre, № 11), pp. 115-132.
} 
una segunda sentencia, la que puede ser de cumplimiento efectivo en algunos casos ( $v$. gr. un reincidente sin irreprochable conducta anterior).

Pero quizás lo más importante, es que mis críticos olvidan el volumen de procesos que ha permitido administrar esta nueva institucionalidad (Reforma Procesal Penal) y específicamente la significancia del número de condenados en términos reales. Pues bien, si seguimos las estadísticas esgrimidas por mis contradictores (Ministerio Público del año 2011), resulta que el total de condenados a nivel nacional ascendió a 241.332, de los cuales 119.821 (49,6\%) correspondió a imputados llevados a audiencia de control de detención (ACD) y $121.511(50,4 \%)$ se realizaron a imputados no llevados a ACD. Del primer segmento, esto es, de imputados llevados a ACD, las condenas a una pena privativa de libertad y sin beneficio ascendió al 38,3\%, esto es, algo más de 45 mil personas; por su parte en el segundo segmento, o sea, casos que no registraron ACD, los condenados a una pena privativa de libertad sin beneficio fue del 15,9\%, algo más de 19 mil personas ${ }^{11}$. Así las cosas, podemos llegar a dos conclusiones: la primera, es que en términos absolutos el total de condenados a una pena privativa de libertad, sin beneficios, informados por esta institución, prácticamente supera la población penal reportada por Gendarmería de Chile para ese mismo año, y; la segunda, es que por muy ínfima que sea la cifra de condenados a una pena de cárcel efectiva en relación al global de términos, hay que verificar su significancia en términos absolutos, la que para el caso concreto supera evidentemente la oferta carcelaria real de plazas disponibles.

En lo que respecta a la tercera crítica, relativa a que el estudio afirma la existencia de leyes que favorecerían el encarcelamiento y, en consecuencia, el aumento de los tiempos de privación de libertad, mis críticos se centran en la multa impaga, y si bien reconocen que ha venido a engrosar injustificadamente la población penitenciaria ${ }^{12}$, constituyendo un $13,26 \%$ del total del sistema cerrado durante el año 2010, indican que no se pone énfasis en el tiempo que efectivamente se permanece en prisión por causa de una multa, el cual promedia 6,19 días. Si bien es correcto que no se hizo hincapié en el tiempo de privación de libertad, esto es debido a que esa variable es intrascendente para los fines del estudio cuestionado, en particular, conocer por qué incrementa la población penal. En efecto, el tiempo de privación de libertad no incide en la frecuencia absoluta de los privados de libertad o, dicho de otro modo, el ejercicio de la medición del número de población penal no se altera porque un preso por

\footnotetext{
11 Ministerio Público (2011): "Boletín Estadístico", p. 5. Disponible en: http://www.fiscaliadechile.cl/ Fiscalia/estadisticas/index.do. [visitado el 25/12/2013].

${ }^{12}$ Lo cual también se reconoce en otros estudios: WelsCH, Gherman; MuÑOz, Nicolás (2012): "La pena de multa en Chile y su efecto en la población penal", en: Conceptos ( $\left.N^{\circ} 25\right)$, pp. 1-20, pp. 7 y ss.
} 
multa impaga esté 1 día o 365 días privado de libertad, sino porque ese preso esté el día en que se mide la población ${ }^{13}$, pudiendo ocurrir la paradoja que los condenados a pocos días sean parte de la cuantificación penitenciaria. En concreto, la multa impaga vino a incrementar la población penitenciaria no porque una persona estuvo mayor o menor tiempo privado de libertad, sino porque el sistema procesal antiguo permitía la sustitución de la multa por la reclusión parcial y el nuevo sistema procesal penal lisa y llanamente no contempló esta alternativa, sino solo y bien parcialmente con la dictación de la Ley № 20.587 -y solo a partir de junio de 2012-, permite dejar sin efecto el apremio y sustituir una multa por prestación de servicios en beneficio de la comunidad.

Por su parte, la observación de mis críticos en relación a que no ha aumentado el tiempo promedio de privación de libertad frente a lo manifestado en el estudio cuestionado, que sostiene justamente lo contrario, sustentado en algunos cambios legislativos, en especial las modificaciones a la ley de drogas y de los delitos contra la propiedad -que aumentaron sus penas privativas de libertad-, debo indicar que si bien mis contradictores aciertan en que el estudio se centra en un espectro teórico más que empírico que pueda justificar la tesis, no es menos cierto que los egresos de prisión frente a los ingresos han bajado bruscamente, como se corroboró con cifras. Como se indicó, el sistema carcelario en los últimos diez años, deducidos los egresos frente a los ingresos, ha debido absorber una demanda de plazas superior a las 28 mil personas. La causa de lo anterior podría venir dada por una multiplicidad de factores que de manera aislada o en conjunto podrían contribuir a ese resultado. Frente a ello, sin duda que las modificaciones legales antes aludidas se presentan como una de las probables causas.

Mención aparte merece el estudio de Peña y Lillo, titulado "Tiempo promedio de duración de las condenas en Chile. Análisis de casos" $^{\prime 14}$, citado por mis contradictores y esbozado públicamente por el Profesor Matus para sustentar que en Chile, específicamente en la Región Metropolitana, ha "disminuido radicalmente" el tiempo promedio de privación de libertad de los Delitos de Mayor Connotación Social (DMCS) ${ }^{15}$, con lo que se restaría crédito a mi proposición. Este estudio, basado en los tiempos promedios de permanencia de presos condenados por DMCS y drogas en algunas Unidades penales de la Región Metropolitana en los años 2003 y 2008 respectivamente, no solo adolece de

\footnotetext{
${ }^{13}$ La construcción de las Estadísticas de Población Penal (sistema cerrado) se basan en las existencias del último día mensual calendario y esto se suma en los doce meses para obtener el resultado anual.

14 Peña y Lillo, María Carolina (2012): "Tiempo promedio de duración de las condenas en Chile. Análisis de casos", Memoria para optar al grado de Licenciado en Ciencias Jurídicas y Sociales, Universidad de Chile, Dir: JP Matus.

${ }^{15}$ Véase diario El Mercurio de 19 de junio del año 2012.
} 
rigor metodológico, como ya fuese puesto de manifiesto por el aportante de los datos (Gendarmería de Chile) que sirvieron para la confección del informe ${ }^{16}$, sino que tampoco basado en él se pueden fundamentar las conclusiones que se alcanzaron, las que tampoco se condicen con otros estudios afines que demuestran, al igual que el cuestionado, una situación distinta.

Vamos por partes, en lo que se refiere a la metodología empleada en esa investigación, debemos señalar que la autora hace un contraste entre el antiguo sistema procesal penal (año 2003) y el nuevo conocido como Reforma Procesal Penal (año 2008), y de esta manera sostiene el mayor rigor punitivo del antiguo sistema versus el benevolismo -bordeando la prevaricación- del segundo. Para este cotejo, se ocupa de los condenados por DMCS y de drogas ingresados al sistema cerrado en tres recintos de la Región Metropolitana (Centro de Cumplimiento Penitenciario de Buin, Centro de Detención Preventiva Santiago Sur y Centro Penitenciario Femenino). Sin perjuicio de ser un censo y no una muestra estadísticamente significativa, comete errores de base que creo van en desmedro de las conclusiones alcanzadas. A primera vista, como lo que se intenta es comparar dos períodos, no solo no se sabe cuál es la muestra de cada año, sino tampoco su distribución por delito ${ }^{17}$. Esta cuestión no es pueril, sino crucial, porque si una muestra es ínfima, por ejemplo, sus resultados no serán representativos de una tipología delictiva en particular. También y con poca claridad, los años comparados devienen en una sola muestra y no en dos, como la experiencia manda que se requiere para hacer el cotejo que se propone. A lo anterior se suma que la autora realiza una serie de depuraciones a la muestra que, seguramente, también alteran sus conclusiones. Primeramente extrae a aquellas personas que no han cumplido una pena y también limpia aquellos casos de condenas múltiples (varios delitos). Estos casos excluidos podrían tener una alta incidencia en la muestra y, sobre todo, en los resultados del año 2008, ya que tratándose del caso de las "condenas no cumplidas", aparentemente quedaron fuera de estudio las que corren entre el año base de medición comparativa (2008) hasta la fecha de obtención de los datos para la elaboración del estudio (2011), es decir, se considera tan sólo un lapso de 4 años que podría explicar por qué los promedios de permanencia en el año 2008 nunca superan los 1.460 días (365 días x 4 años), situación que se advierte especialmente en los delitos graves.

\footnotetext{
${ }^{16}$ El Subdirector Técnico de Gendarmería si bien reconoce la aportación de los datos para la confección del estudio de la alumna Peña y Lillo, pone de manifiesto la necesidad de la validación de los datos para evitar omisiones o interpretaciones erradas, como las que sugiere en distintos tópicos. Véase diario El Mercurio de 27 de junio de 2012.

17 La autora describe una muestra total para el año 2003 de 1.931 casos y de 10.821 para el año 2008, sin depuraciones y sin distribución por delitos.
} 
Por otro lado, ese estudio no se basa en las condenas impuestas por los tribunales con competencia criminal, sino sólo en los tiempos de permanencia en los penales ya referidos, conforme a los datos informados por Gendarmería de Chile (Genchi). Sin embargo, como también indicó Genchi públicamente ${ }^{18}$, estas estadísticas consideran un elemento del cual no se hace cargo la investigadora y que también pueden modificar sus conclusiones, como son los "traslados de Unidad Penal", equivalentes a un egreso para Genchi y respecto de los cuales se hace-erradamente- sinónimo de un cumplimiento de condena ${ }^{19}$.

Sin perjuicio de lo anterior, quizás el problema más grave de ese estudio es que sus datos generan desconfianza desde la óptica jurídico-penal y no guardan consistencia con otros estudios similares y distintos al cuestionado. Así, por ejemplo, revisando algunas cifras del estudio de la autora, encontramos que los condenados por delito de hurto en el recinto penitenciario de Santiago Sur, en el año 2003, alcanzaron un promedio de 1.318,4 días (3 años y medio ); cifra que no sólo se ubicó cercana al delito de homicidio (1.448,7 días), sino que también desde el punto de vista del Derecho penal aparentemente está referida de manera única y excluyente a los hurtos más graves del artículo 446 $N^{\circ} 1$ del Código o a los hurtos calificados del artículo 447, en circunstancias que los hurtos que más se cometen, como dicta la experiencia, son de cosas de bajo valor monetario y que tienen una pena manifiestamente inferior. Una mayor vacilación generan los datos presentados a propósito del delito de homicidio en todos los recintos censados en el año 2008, donde el promedio efectivo de condenas por este delito es de 744 días (2 años y algunos días), cifra que a simple vista debe ser puesta en duda y que Genchi tuvo que aclarar y corregir ${ }^{20}$, señalando que el promedio correcto es de 2.927 días, dato muy superior al aportado en esa investigación e inmensamente superior al que se informa para el año 2003 (1.448 días). Además de lo antes indicado, las cifras están inconexas con otros estudios fundamentales sobre la materia que fueron realizados por Paz Ciudadana, en el que se comparan las penas impuestas por sentencia en los delitos de mayor connotación social y delitos de tráfico de drogas en los años 2002 (sistema antiguo) y 2006 (reforma procesal penal) respectivamente. Concluyendo que la implementación de la Reforma Procesal Penal no ha producido una menor aplicación de la pena de cárcel tratándose de estos delitos. Además, se constató en el estudio del año 2006, al igual que

\footnotetext{
${ }^{18}$ Véase diario El Mercurio de 27 de junio de 2012.

${ }^{19}$ Para que se reconozca la incidencia, por ejemplo en el año 2008 los traslados de condenados de Santiago Sur ascendieron a 2.632 personas. Cabe resaltar que no se trataba de personas que habían cumplido la pena.

${ }^{20}$ Véase diario El Mercurio de 27 de junio de 2012.
} 
en su predecesor del 2002, que la pena más aplicada a cada ilícito se ubica en el límite inferior del rango legal y que no obstante estos ilícitos tengan asignada una pena privativa de libertad, en la práctica sólo una fracción menor de los condenados cumple su sanción en un recinto penitenciario ${ }^{21}$. Claro que debemos dejar de manifiesto que esto ocurre tanto en el antiguo como en el nuevo sistema procesal penal. Pero quizás los datos más contradictores de lo dicho por mis críticos en comparación a los estudios de Paz Ciudadana, es que sustentan a propósito del delito de homicidio una diferencia entre las condenas del año 2003 y 2008, que varía entre aproximadamente un 20\% y 400\% (dependiendo del recinto penitenciario). En cambio, Paz Ciudadana indica en sus informes que las condenas por homicidio están dentro del rango legal (5 años y 1 día de presidio mayor en su grado mínimo a presidio perpetuo calificado) en los años 2002 y 2006, no habiendo una diferencia significativa y que están solo separados por 3 puntos porcentuales ${ }^{22}$.

La última crítica está referida a la aplicación de la Ley № 18.216 como factor que ayude a descomprimir los recintos penitenciarios. Se sostiene un uso extensivo de esta ley por parte de los tribunales, lo que le restaría crédito a la afirmación de ausencia de mecanismos idóneos de descompresión carcelaria. Sin embargo, lo defendido en el trabajo cuestionado es un uso reducido de los "beneficios penitenciarios" como la libertad condicional y no de esta ley que establece beneficios alternativos a la privación de libertad. Sobre este último punto, se reconoce y se aportan datos sobre el uso generalizado de este instrumento legal. El problema final, es que este no es un instrumento idóneo para combatir la sobrepoblación, ya que no opera ex-post de la sentencia condenatoria, sino al momento mismo de la imposición de la pena.

Para ir cerrando estas líneas y agradecer el debate propuesto, se puede decir en conclusión que no podemos afirmar empíricamente, como postulan mis críticos, que la población penal en Chile ha crecido por un incremento de la actividad criminal, máxime cuando esta situación no guarda correspondencia con la ENUSC y los postulados de mis contradictores no son satisfactorios. Pareciera que las respuestas que entregué en el trabajo cuestionado podrían

\footnotetext{
${ }^{21}$ Valdivia Rivas, Claudio (2007): "Estudio empírico de penas en Chile 2006", en: Fundación Paz Ciudadana e Instituto de Sociología Pontificia Universidad Católica de Chile, presentado en el tercer simposio nacional de investigación sobre violencia y delincuencia. Disponible en: www.pazciudadana. cl [visitado el 25/12/2013]; Hurtado, Paula; Jünemann, Francisca (2002): "Estudio empírico de penas en Chile 2002". Disponible en: www.pazciudadana.cl [visitado el 25/12/2013].

22 En el año 2002, las condenas que están dentro del rango legal alcanzan al 52\% y en el año 2006 al 49\%. A su vez, las condenas que están bajo el rango legal en 2002 alcanzan al $48 \%$ y en 2006 al $51 \%$.
} 
ser plausibles y guardan una coherencia teórica y con otros estudios empíricos sobre el tema.

Afirmaciones como que la Reforma Procesal Penal en cortos tiempos de tramitación procesal asegura que los imputados no recibirán pena alguna o, en caso de recibirla, ésta será de corta duración -situación también conocida como "puerta giratoria"-, no tienen un correlato basado en la experiencia y que, por lo demás, justifique el incremento en todos los años de la población penitenciaria, que avale el $60 \%$ de sobrepoblación (hacinamiento) y la necesaria y prometida creación de nuevas cárceles para absorber una demanda de 9 mil plazas. 